|| ISSN(online): 2589-8698 || ISSN(print): 2589-868X ||

International Journal of Medical and Biomedical Studies Available Online at www.ijmbs.info

NLM (National Library of Medicine ID: 101738825)

Index Copernicus Value 2020: 79.44

Case Report

Volume 6, Issue 01; January: 2022; Page No. 78-81

\title{
DUODENAL HETEROTOPIA IN GALL BLADDER - A RARE AUTOPSY CASE REPORT
}

\section{Dr. Promil Jain ${ }^{1}$, Dr. Niti Dalal ${ }^{2}$, Dr. Veena Gupta ${ }^{3}$, Dr. Rajeev Sen ${ }^{4}$}

${ }^{1}$ Associate Professor, Department of Pathology, PGIMS, Rohtak

${ }^{2}$ Senior Resident, Department of Pathology, PGIMS, Rohtak

${ }^{3}$ Professor, Department of Pathology, PGIMS, Rohtak

${ }^{4}$ Senior Professor \& Head, Department of Pathology, PGIMS, Rohtak

Article Info: Received 19 December 2021; Accepted 21 January 2022

DOI: https://doi.org/10.32553/ijmbs.v6i1.2377

Corresponding author: Dr. Niti Dalal

Conflict of interest: No conflict of interest.

\begin{abstract}
Heterotopic duodenal tissue in the Gall Bladder is an extremely rare incidental post mortem finding with unknown clinical significance. Gastric and pancreatic heterotopia is the most common heterotopic tissue found in the gastrointestinal tract. Gall bladder is rarely involved with unknown prevalence rate. It may be associated with cholecystitis or cholecystolithiasis. Etiology of heterotopia is still unknown. We report an autopsy case of a 36-year-old-man with an incidental duodenal heterotopia in gall bladder.
\end{abstract}

Keywords: Duodenum, heterotopia, gall bladder, autopsy

\section{Introduction}

In Pathology, term heterotopia is defined as the presence of the normal tissue in an abnormal location, without any neural, vascular, or anatomic connection with the main organ. Term Choristoma has been used synonymously. ${ }^{\mathbf{1}, 2}$ Gastric heterotopia refers to presence of normal gastric mucosal tissue at a non-physiologic site, separate from the surrounding mucosa and entirely separate from stomach. It is a commonly reported epithelial heterotopia, also known as heteroplasia (congenital) during organogenesis or metaplasia (acquired) during the process of epithelial repair. Gastric heterotopia has been reported in the gastrointestinal tract, anywhere from mouth to anorectal area and also in hepatobiliary system. ${ }^{3}$ Pancreatic and gastric heterotopia are the most common. Duodenal heterotopia is an extremely uncommon form of heterotopia. Only few cases have been reported in literature, involving stomach, ileum and gall bladder. ${ }^{4,5,6,7}$ Duodenal heterotopia is mostly asymptomatic and rarely gives rise to any complications. $^{8}$

\section{CASE HISTORY}

A 36-year-old-man reported to emergency with complaints of fever, shortness of breath for a few days. While, he was being treated for extensive bilateral pneumonitis, he died on second day of admission due to respiratory complications. We, in the Department of Pathology, received post mortem viscera of the deceased for histopathological examination, which included brain, heart, portion of lung, liver along with attached gall bladder, spleen and kidneys. Grossly, lung showed firm, grey red areas while gross examination of gall bladder revealed unremarkable outer surface. On cutting open, mucosal surface was grey brown to green in colour with wall thickness measured $0.3 \mathrm{~cm}$ in diameter (Figure 1). No area of thickening or discoloration was seen. Microscopic examination of gall bladder revealed partially autolysed superficial gall bladder mucosa with presence of Brunner's gland in mucosa and submucosa. Underlying muscularis propria was normal. Microscopic sections examined from lung showed features of pneumonitis (Figure 2). All others organs were unremarkable. 


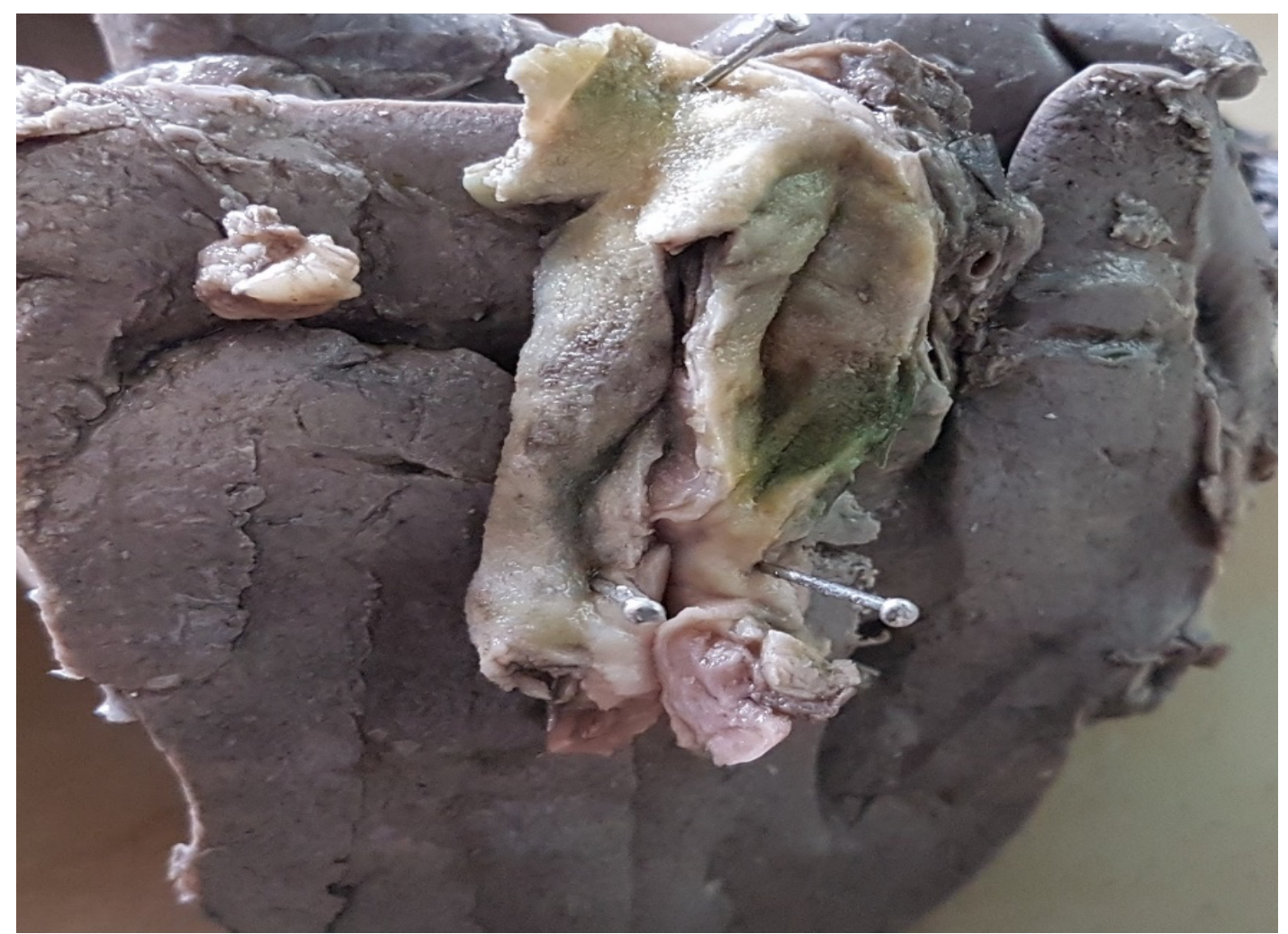

\section{Figure 1: Gross specimen of Gall Bladder is unremarkable}

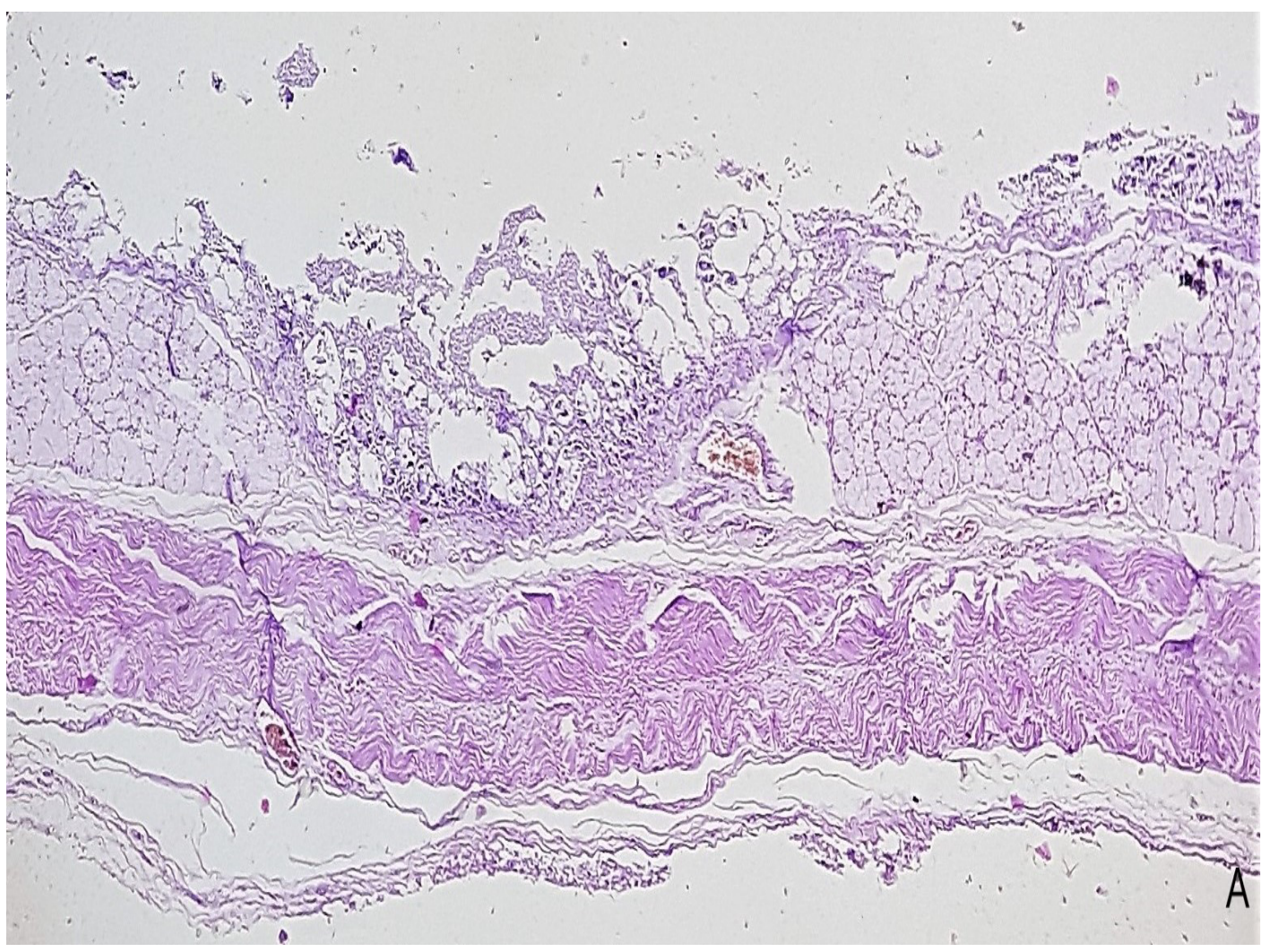




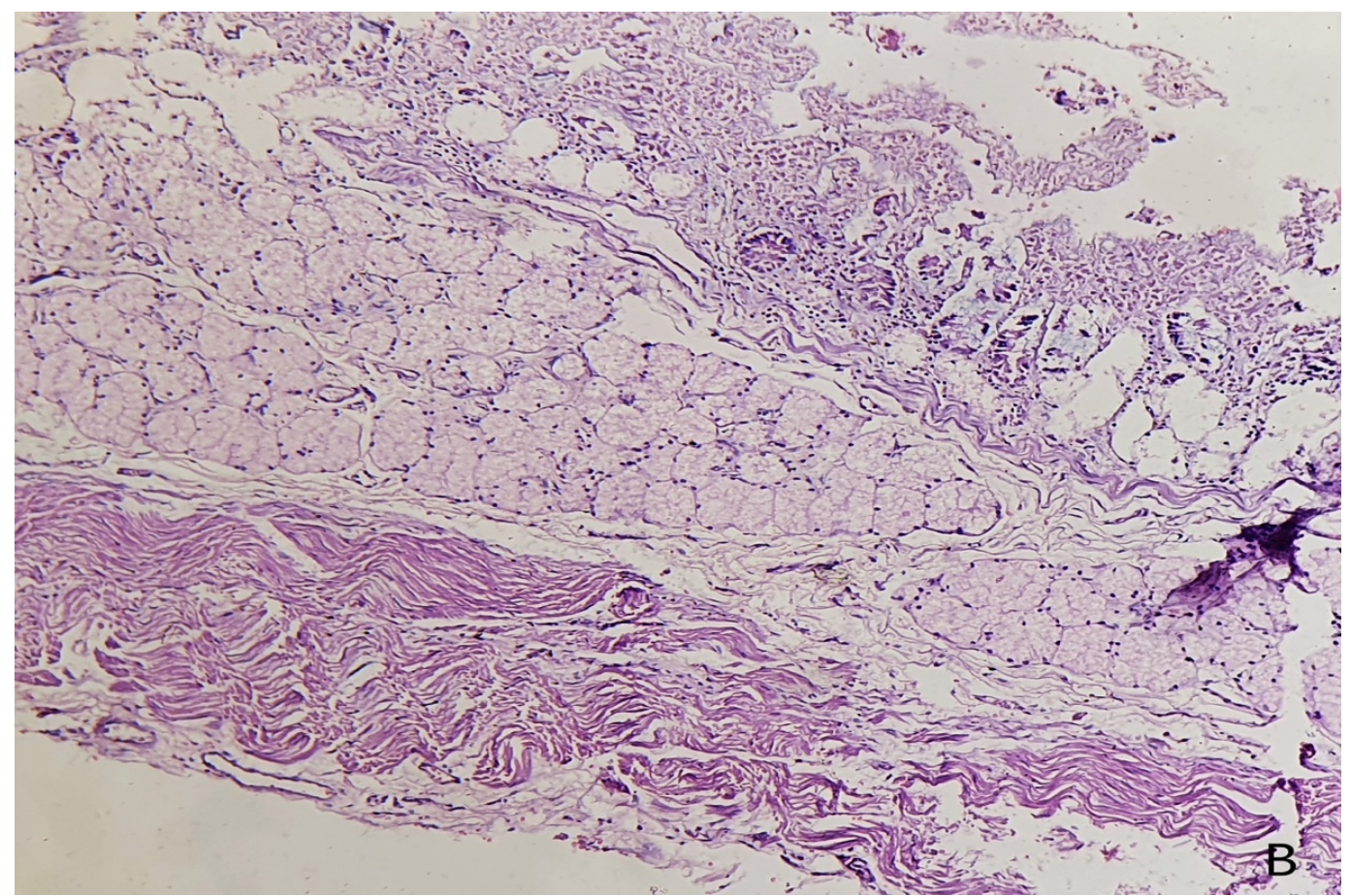

Figure 2: A: Low power view of Gall Bladder showing brunner's gland heterotopia in its wall $(\mathrm{H} \& \mathrm{E}, 100 \mathrm{X})$; $\mathrm{B}$ : High power view of Gall Bladder showing brunner's gland heterotopia in its wall (H\&E, 400X)

\section{Discussion}

Gastrointestinal (GI) heterotopias are commonly reported lesions that have been found throughout the gastrointestinal tract. The postulated etiology of GI heterotopias is that these are either congenital anomalies, arising due to abnormalities during rotation of the foregut or due to metaplasia. Cases of GI heterotopias have been reported with variable clinical presentation, depending on the nature of primary tissue, its size, location and associated complications. ${ }^{4}$ Most GI heterotopias are Gastric and pancreatic heterotopia, with an incidence of $1-13 \%{ }^{2,4}$ Most frequent reported heterotopia are pancreatic heterotopia seen in stomach or gastric mucosa while gastric and pancreatic heterotopia seen in duodenum and jejunum. Duodenal heterotopia is a rarest form of heterotopia discovered incidentally. ${ }^{4}$ Its prevalence, significance and clinical presentation could not be ascertained due to is lack of case studies in the literature. Clinically, patient may be asymptomatic or may present with non-specific gastrointestinal symptoms. ${ }^{2}$ Despite extensive search of the literature, we could find only four cases of duodenal heterotopia, two in stomach and one each in ileum and gall bladder. Heterotopia was detected in a case of gastric adenomyoma, leading to pyloric obstruction. In second case, it was found in a patient suffering from carcinoma stomach. In another case, duodenal tissue was detected on histopathological examination of distal ileum. In yet another case, duodenal tissue was an incidental microscopic finding in gall bladder which was removed due to acute and chronic cholecystitis with cholelithiasis and choledocholithiasis. ${ }^{4,5,6,7}$ In our case, we incidentally found Brunner's gland in wall of gall bladder while examining autopsy viscera of a patient who died due to unrelated respiratory complications. To the best of our knowledge, this is second case report of duodenal heterotopia in gall bladder. ${ }^{7}$ Preoperative diagnosis is not possible both clinically or radiologically. ${ }^{9}$ However, careful histopathological examination of cholecystectomy specimens is essential for its diagnosis. ${ }^{8}$ The clinical significance of this heterotopia is still unknown. ${ }^{4}$ Dysplasia and potential for carcinogenesis had been described only in gastric heterotopia till date. ${ }^{2}$ Most of the heterotopias of GI tract are mainly of academic interest.

\section{Conclusion}

Duodenal heterotopia of the gallbladder is a rare entity with unknown clinical significance. Our case report is an addition to the literature of this rare entity. Awareness of heterotopia is important as these might present a difficulty in terms of differential diagnosis with neoplasia.

\section{Acknowledgement}

All the authors have contributed to concept, data analysis, manuscript editing and review. There was no prior abstract/poster presentation and publications related to this topic. 


\section{References}

1. Xeropotamos N, Skopelitou AS, Batsis C, Kappas AM. Heterotopic gastric mucosa together with intestinal metaplasia and moderate dysplasia in the gall bladder: report of two clinically unusual cases with literature review. Gut. 2001;48:719-23.

2. Pendharkar D, Khetrapal S, Jairajpuri ZS, Rana S, Jetley S. Pancreatic and gastric heterotopia in the gallbladder: A rare incidental finding. Int J App Basic Med Res. 2019;9:115-7.

3. Dinarvand P, Vareedayah AA, Phillips NJ, Hachem C, Lai J. Gastric heterotopia in rectum: A literature review and its diagnostic pitfall. SAGE Open Med Case Reports. 2017;5:1-5.

4. Kumar T, Punia RS, Kaushik R, Singh S. Duodenal heterotopia in the distal ileum. Clin Case Rep Rev. 2017;3(3):1-2.
5. Berant M, Aviad I, Jacobs J. Heterotopic duodenal mucosa in the stomach. Am J Dis Child. 1965;110: 566-9.

6. Johnson CD, Bynum TE. Brunner Gland Heterotopia presenting as Gastric Antral Polyps. Gastrointest Endosc. 1976;22: 210-11.

7. Galloway PG. Heterotopic duodenum in the cystic duct. Archives Pathol Laboratory Med. 1984.108(8):666-8.

8. Al-Shraim M, Rabie ME, Elhakeem H, Kandeel A, Shah MT, Jamil S. Pancreatic Heterotopia in the Gallbladder Associated with Chronic Cholecystitis: A Rare Combination. JOP J Pancreas (Online). 2010;11(5):464-6.

9. Elhence P, Bansal R, Agrawal N. Heterotopic pancreas in gall bladder associated with chronic cholecystolithiasis. Int $\mathrm{J}$ App Basic Med Res. 2012;2:142-3. 